\title{
Use of dipeptidyl peptidase 4 inhibitors and fracture risk compared to use of other anti-hyperglycemic drugs
}

\author{
Johanna H. M. Driessen ${ }^{1,2,3}$, Hein A. W. van Onzenoort ${ }^{3,4}$, Jakob Starup-Linde ${ }^{5,6}$, Ronald Henry ${ }^{7,8}$, Cees Neef ${ }^{2,3}$, \\ Joop van den Bergh ${ }^{9,10}$, Peter Vestergaard ${ }^{5,11}$, Frank de Vries ${ }^{1,2,3,12 *}$ and Andrea M. Burden ${ }^{1,2,3}$ \\ ${ }^{1}$ Division of Pharmacoepidemiology and Clinical Pharmacology, Utrecht Institute of Pharmaceutical Sciences, Utrecht, The Netherlands \\ ${ }^{2}$ Care and Public Health Research Institute (CAPHRI), Maastricht, The Netherlands \\ ${ }^{3}$ Department of Clinical Pharmacy and Toxicology, Maastricht University Medical Centre+, Maastricht, The Netherlands \\ ${ }_{5}^{4}$ Department of Pharmacy, Radboud University Nijmegen Medical Centre, Nijmegen, The Netherlands \\ ${ }^{5}$ Department of Clinical Medicine, Aalborg University, Aalborg, Denmark \\ ${ }^{6}$ Department of Endocrinology and Internal Medicine, Aarhus University Hospital, Aarhus, Denmark \\ ${ }^{7}$ Department of Medicine, Maastricht University Medical Centre+, The Netherlands \\ ${ }^{8}$ Cardiovascular Research Institute Maastricht, Maastricht University Medical Centre+, The Netherlands \\ ${ }^{9}$ Department of Internal Medicine, Maastricht University Medical Centre+, The Netherlands \\ ${ }^{10}$ Biomedical Research Institute, University Hasselt, Hasselt, Belgium \\ ${ }^{11}$ Department of Endocrinology, Aalborg University Hospital, Aalborg, Denmark \\ ${ }^{12}$ MRC Epidemiology Lifecourse Unit, Southampton General Hospital, Southampton, UK
}

\begin{abstract}
Introduction Dipeptidyl peptidase-4 inhibitors (DPP4-Is) are a new class of anti-hyperglycemic drugs which might have a potential beneficial effect on bone metabolism. Data on the effect of DPP4-I use and fracture risk is limited and conflicting. The aim of the present study was to investigate the association between use of DPP4-Is and fracture risk.

Methods A case-control study was conducted using data from the Danish National Health Service. Cases were those who sustained a fracture, and controls were those without a fracture during the study period (2007-2011), all aged 18 years and older. Conditional logistic regression estimated the odds ratios of fracture with current use of DPP4-I use. Analyses were adjusted for comorbidities and recent drug use.

Results Among the cases there were 6993 current non-insulin anti-diabetic drug (NIAD) users (excluding incretin users) and 643 DPP4-I users. There were 7209 NIAD users (excluding incretin users) among the controls and 707 DPP4-I users. Current DPP4-I use was not associated with risk of any fracture (adjusted [adj.] OR: 0.97, 95\% CI: 0.79-1.18) or major osteoporotic fracture (adj. OR: 0.96, 95\% CI: 0.721.28). Stratification of current DPP4-I use to cumulative and average daily dose did not show an association.

Conclusions In a population-based case-control study we identified that short-term use of DPP4-I was not associated with fracture risk as compared to users of other anti-hyperglycemic drugs. Additionally, results suggest that increasing daily dose and cumulative DPP4-I exposure were not associated with fracture risk. However, more research is needed to assess the effect of long-term DPP4-I use on the risk of fracture. Copyright (C) 2015 John Wiley \& Sons, Ltd.
\end{abstract}

KEY WORDS-DPP4-I; fracture; type 2 diabetes mellitus; case-control; pharmacoepidemiology

Received 11 February 2015; Revised 1 May 2015; Accepted 22 June 2015

\section{INTRODUCTION}

Individuals with type 2 diabetes are at an excess risk of osteoporotic fractures. ${ }^{1}$ Although the etiology of this increased risk is largely unknown, it has been

\footnotetext{
*Correspondence to: F. de Vries, Division of Pharmacoepidemiology and Clinical Pharmacology, Utrecht Institute for Pharmaceutical Sciences, Utrecht University, The Netherlands. E-mail: f.devries@uu.nl
}

hypothesised that this might be because of the underlying disease and/or to the drugs used in the treatment of type 2 diabetes. ${ }^{2,3}$ For instance, thiazolidinediones have been associated with an increased fracture risk as compared to use of other anti-hyperglycemic drugs. ${ }^{4-6}$ Moreover, epidemiological studies have shown that insulin use is associated with an elevated risk of fracture, ${ }^{7}$ whereas metformin has been associated with a decreased risk of fracture. ${ }^{8}$ 
Dipeptidyl peptidase 4 inhibitors (DPP4-Is), such as sitagliptin, vildagliptin and saxagliptin, are a new class of anti-hyperglycemic drugs, which may positively affect bone metabolism ${ }^{3}$ and decrease fracture risk. DPP4-Is inhibit the degradation process of incretin hormones, such as glucose-dependent insulinotropic polypeptide (GIP) and glucagon-like peptide-1 (GLP1 ), which are secreted shortly after food ingestion. ${ }^{3}$ Thus, DPP4-Is prolong the half-life time of the incretin hormones. In vitro research has shown that there are GLP-1 receptors present on osteocytes ${ }^{9}$ and immature osteoblast cells. ${ }^{10}$ Activation of this receptor leads to an increased bone formation and an inhibition of bone resorption, ${ }^{5,11}$ which might result in a decreased fracture risk.

Prior evidence on the association between DPP4-I use and risk of fracture are conflicting and limited mostly to clinical trial data. A meta-analysis of clinical trials showed a $40 \%$ reduction in fracture risk associated with DPP4-I use. ${ }^{12}$ However, the study had several limitations: the total number of fractures was small, fracture was not a primary endpoint and fractures were not routinely collected, there were heterogeneous comparison groups and it might be that relatively healthy patients were included in the trials. A large clinical trial $(n=16492$, with a median follow-up time of 2.1 years), comparing saxagliptin to placebo, showed a relative risk of fracture around $1 .{ }^{13}$ An observational study investigating the effect of DPP4-I use on fracture risk showed a hazard ratio of 1.03 (95\% confidence interval $[\mathrm{CI}]$ 0.92-1.15) as compared to use of other anti-hyperglycemic drugs. ${ }^{14}$

With limited available data, the aim of the present study was to examine the association between use of DPP4-Is and fracture risk compared to use of other anti-hyperglycemic drugs in a population based casecontrol study.

\section{METHODS}

\section{Data source}

In Denmark, the extensive nature of health registries, covering all contacts to the health sector, offers the possibility for large population based studies on the occurrence of fractures. ${ }^{15}$ Using the unique 10-digit civil registry number that is assigned to all Danish citizens shortly after birth, a complete hospital discharge and prescription history can be established for each individual, and permits valid linkage between population-based registries. ${ }^{16}$ Data on all changes in vital status, including change of address and date of death for the entire Danish population, are registered since 1968 in the Civil Registration
System. The Danish National Hospital Discharge Register ${ }^{17}$ was founded in 1977 and covers all inpatients contacts from 1977 to 1994. Additionally, all outpatient visits to hospitals, outpatient clinics and emergency rooms have been collected since 1995.

In Denmark, pharmacies are equipped with a computerised accounting system through which data are sent directly to a Register of Medicinal Product Statistics (i.e. a prescription database) at the Danish Medicines Agency with key information on prescriptions for refundable drugs. The prescription database includes information on patient's civil registry number, the type and amount of drug prescribed according to the Anatomical Therapeutic Chemical (ATC) classification system and the date when the prescription was filled. The database was started on 1 January 1996 and updated hereafter.

The Danish population constituted approximately 5.2 million individuals in 1995 and 5.5 million in 2011. The study was subject to control by the National Board of Health and the Danish Data Protection Agency.

\section{Study design}

We conducted a population based case-control study. Cases were all subjects, both genders and aged 18 years and older, who sustained a fracture (International Classification of Diseases and Related Health Problems [ICD]-10 codes: S02, S12, S22, S32, S42, S52, S62, S72, S82, S92, T02, T08, T10 and T12) between 9 May 2007 (the first ever prescription of a DPP4-I in Denmark) and 31 December 2011. Information on fractures was on based in-patient and outpatient hospital records. Controls were all subjects, both genders and aged 18 years and older, who did not sustain a fracture during the study period. We randomly selected one control for each case, matched by gender and year of birth by means of the incidencedensity sampling technique. ${ }^{18}$ The date of the first fracture was used as index date, and controls were assigned the index date of their matched case. The following categories were used to further classify fractures: hip (S72.0-S72.2), radius/ulna (S52) and vertebrae (S12, S22.0-S22.1, S32.0-S32.2, S32.7, S32.8 and T08). A major osteoporotic fracture was defined as a fracture of the hip, radius/ulna, vertebrae or humerus (S42.2S42.4) according to the WHO definition. ${ }^{19}$

\section{Exposure of interest}

We explored all drugs bought during the observation period available in the database. The dose of the drug bought during the observation period was expressed as defined daily dose (DDD). ${ }^{20}$ ATC code A10B was 
used to determine exposure to non-insulin antidiabetic drugs (NIAD). Based on the time of the most recent prescription before the index date, patients were classified as current (1-91 days) or past (over 91 days) NIAD user. Current NIAD users were divided into two mutually exclusive categories: never (during the study period) incretin users and incretin users. As diabetes itself might act as a confounder ${ }^{2}$ we used never incretin users (i.e. patients using non-insulin anti-diabetic drugs excluding incretins) as the reference category in our analysis. Incretin use was further divided into glucagon-like peptide-1 receptor agonist (GLP-1 RA) users and DPP4-I users. DPP4-I exposure was determined by use of ATC codes A10BD07A10BD13 and A10BH. DPP4-I users were classified as current (1-91 days), recent (92-182), past (183365 days) or distant (over 365 days) users based on the time since the most recent prescription before the index date.

The DDDs were used to estimate the cumulative dose of DPP4-I for each current DPP4-I user, expressed as sitagliptin equivalents. The average daily dose was estimated by dividing the cumulative exposure by the treatment time (time between the first DPP4-I prescription and the index date).

\section{Potential confounders}

We considered the following potential confounders ever before the index date: a history of chronic obstructive pulmonary disease (COPD), previous fracture, rheumatoid arthritis, hypothyroidism, hyperthyroidism, cancer, alcoholism, retinopathy, secondary osteoporosis (diabetes type 1, hypogonadism or premature menopause) and congestive heart failure. The potential confounders were determined by use of the National Hospital Register based on ICD10 and ICD8 codes. Other potential confounders included a prescription in the 6 months before the index date of the following drugs: GLP-1 RA, oral glucocorticoids, ${ }^{21}$ cholesterol lowering drugs, antidepressants, ${ }^{22}$ anxiolytics, hypnotics, ${ }^{23}$ antipsychotics, anti-Parkinson drugs, ${ }^{24}$ antihypertensives (beta-blockers, thiazide diuretics, renin-angiotensin-aldosterone system (RAAS) inhibitors, calcium channel blockers and loop diuretics) and antiarrhythmics. The prescription database was used to explore the presence of a prescription of the above-mentioned drugs.

\section{Statistical analysis}

Conditional logistic regression was used to estimate the association between the use of DPP4-Is RAs versus use of other anti-hyperglycemic drugs and risk of fracture, using SAS 9.3 software. Analyses were stratified by age, gender, type of fracture and for current DPP4-I use also by average daily and cumulative exposure. As a sensitivity analysis the main analysis was also adjusted for current metformin use, because metformin use has been associated with a decreased risk of fracture. ${ }^{8}$ Final regression models were determined by stepwise backward elimination using a significance level of 0.05 . All results are presented as odds ratios (OR) with corresponding 95\% CI.

\section{RESULTS}

\section{Study population}

We identified 229145 cases and the same number of controls. In both cases and controls, the mean age was 55 years old, and $56 \%$ were females. Baseline characteristics are shown in Table 1 . There were 643 $(0.3 \%)$ cases and $707(0.3 \%)$ controls that were DPP4-I users (current, recent, past or distant). The mean duration of DPP4-I use (time from first prescription till index date) for current DPP4-I use was 47 weeks for both cases and controls.

\section{DPP4-I use and risk of any fracture}

We identified, 6993 (3.1\%) cases and 7209 (3.1\%) controls with current NIAD use (excluding incretin users) (Table 2). Never NIAD use was associated with a slightly increased risk of fracture, adjusted (adj.) OR 1.10 (95\% CI: 1.06-1.14) as well as past NIAD use, adj. OR 1.12 (95\% CI: 1.05-1.20). The risk of any fracture was not associated with current DPP4-I use adj. OR 0.97 (95\% CI: 0.79-1.18), whereas recent use showed a significantly decreased risk of fracture, adj. OR 0.76 (95\% CI: 0.59-0.97). The risk associated with past and distant DPP4-I use was not significantly decreased: adj. OR 0.96 (95\% CI: 0.77-1.20), and adj. OR 0.95 (95\% CI: 0.72-1.25), respectively. There was no decreased risk of fracture after stratification by sex and age (Table 2).

\section{Other fracture types}

Current DPP4-I use was not associated with major osteoporotic fracture risk, adj. OR 0.96 (95\% CI: 0.721.28) (Table 3). Recent DPP4-I use showed a significantly decreased risk of major osteoporotic fracture adj. OR 0.70 (95\% CI: 0.49-1.00), while past and distant DPP4-I use was not associated with a decrease in risk adj. OR 0.95 (95\% CI: 0.71-1.29); adj. OR 0.94 (95\% CI: 0.63-1.38), respectively. DPP4-I use (current, recent, past or distant) was not associated with risk of hip fracture or radius/ulna fracture. Current DPP4-I use was not associated with vertebral fracture 
Table 1. Baseline characteristics*

\begin{tabular}{|c|c|c|}
\hline Characteristic & $\begin{array}{c}\text { Cases } \\
(\mathrm{n}=229145)\end{array}$ & $\begin{array}{c}\text { Controls } \\
(\mathrm{n}=229145)\end{array}$ \\
\hline Women & $127449(55.6)$ & $127449(55.6)$ \\
\hline Mean age at index date (years, SD) & $55(20.6)$ & $55(20.6)$ \\
\hline $18-49$ years & $90598(39.5)$ & $90607(39.5)$ \\
\hline $50-59$ years & $37247(16.3)$ & $37191(16.2)$ \\
\hline $60-69$ years & $38751(16.9)$ & $38805(16.9)$ \\
\hline $70-79$ years & $28950(12.6)$ & $28931(12.6)$ \\
\hline $80+$ years & $33599(14.7)$ & $33611(14.7)$ \\
\hline \multicolumn{3}{|l|}{ History of comorbidities } \\
\hline Type 1 diabetes & $2113(0.9)$ & $1419(0.6)$ \\
\hline Alcoholism & $11147(4.9)$ & $4824(2.1)$ \\
\hline Fracture & $46446(20.2)$ & $15418(6.7)$ \\
\hline Hyperthyroidism & $3715(1.6)$ & $3688(1.6)$ \\
\hline Hypothyroidism & $2887(1.3)$ & $2496(1.1)$ \\
\hline COPD & $10812(4.7)$ & $7418(3.2)$ \\
\hline Congestive heart failure & $7141(3.1)$ & $5424(2.4)$ \\
\hline Cancer & $21893(9.6)$ & $18486(8.1)$ \\
\hline Rheumatoid arthritis & $3912(1.7)$ & $2795(1.2)$ \\
\hline Retinopathy & 3105 (1.4) & $2314(1.0)$ \\
\hline Neuropathy & $7915(3.5)$ & $6093(2.7)$ \\
\hline Secondary osteoporosis & $5284(2.3)$ & $3352(1.5)$ \\
\hline \multicolumn{3}{|l|}{$\begin{array}{l}\text { Drug use within six months before } \\
\text { index date }\end{array}$} \\
\hline Diabetic medication & $8541(3.7)$ & $8676(3.8)$ \\
\hline Biguanides & $6223(2.7)$ & $6678(2.9)$ \\
\hline Sulphonylurea derivatives & $3900(1.7)$ & $3809(1.7)$ \\
\hline Thiadolidinediones & $262(0.1)$ & $183(0.1)$ \\
\hline Glinides & $87(0.0)$ & $83(0.0)$ \\
\hline GLP-1 RAs & $255(0.1)$ & $220(0.1)$ \\
\hline DPP4-Is & $643(0.3)$ & $707(0.3)$ \\
\hline Acarbose & $42(0.0)$ & $28(0.0)$ \\
\hline Insulins & $4900(2.1)$ & $3261(1.4)$ \\
\hline Short acting & $2046(0.9)$ & $1139(0.5)$ \\
\hline Intermediate acting & $2049(0.9)$ & $1411(0.6)$ \\
\hline Long acting & $1444(0.6)$ & $869(0.4)$ \\
\hline Combinations & $1679(0.7)$ & $1200(0.5)$ \\
\hline Statins & $31874(13.9)$ & $32064(14.0)$ \\
\hline Antiarrhythmics & $818(0.4)$ & $522(0.2)$ \\
\hline Beta-blockers & $23281(10.2)$ & $23592(10.3)$ \\
\hline Thiazide diuretics & $20425(8.9)$ & $21547(9.4)$ \\
\hline RAAS inhibitors & $37555(16.4)$ & $39379(17.2)$ \\
\hline Calcium channel blockers & $22942(10.0)$ & $22816(10.0)$ \\
\hline Loop diuretics & $16905(7.4)$ & $12766(5.6)$ \\
\hline Antidepressants & $33644(14.7)$ & $20338(8.9)$ \\
\hline Anti-Parkinson drugs & $3174(1.4)$ & $1814(0.8)$ \\
\hline Antipsychotics & $8032(3.5)$ & $4867(2.1)$ \\
\hline Anxiolytics & $14668(6.4)$ & $10431(4.6)$ \\
\hline Hypnotics & $19137(8.4)$ & $14332(6.3)$ \\
\hline Glucocorticoids & $9390(4.1)$ & $6858(3.0)$ \\
\hline Bisphosphonates & $7371(3.2)$ & $4913(2.1)$ \\
\hline Raloxifene & $214(0.1)$ & $148(0.1)$ \\
\hline Vitamin D & $211(0.1)$ & $169(0.1)$ \\
\hline Calcium & $1885(0.8)$ & $1375(0.6)$ \\
\hline Strontium ranelate & $194(0.1)$ & $101(0.0)$ \\
\hline PTH & $130(0.1)$ & $70(0.0)$ \\
\hline Calcitonin & $2(0.0)$ & $1(0.0)$ \\
\hline Hormone replacement therapy & $11912(5.2)$ & $13955(6.1)$ \\
\hline Beta2-agonists & $10436(4.6)$ & $8130(3.6)$ \\
\hline Inhaled anticholinergics & $4569(2.00)$ & 3277 (1.4) \\
\hline Inhaled corticosteroids & $5265(2.3)$ & $4657(2.0)$ \\
\hline
\end{tabular}

Abbreviations: SD: standard deviation; GLP-1 RAs: glucagon-like peptide1 receptor-agonists; DPP4-Is: dipeptidyl peptidase 4 inhibitors; COPD: chronic obstructive pulmonary disease; RAAS: renin angiotensin aldosterone system; PTH: parathyroid hormone.

*Data are number $(\%)$ of patients, unless stated otherwise. risk whereas recent DPP4-I use resulted in a decreased risk of vertebral fracture: adj. OR 0.27 (95\% CI: 0.080.90). Past and distant use was not associated with a decreased risk of vertebral fracture: adj. OR 2.34 (95\% CI: 0.87-6.32), adj. OR 1.01 (95\% CI: 0.254.12), respectively. Stratification by gender did not result in a reduced fracture risk for women or men (data not shown).

\section{Current DPP4-I use stratified by cumulative and average daily dose and fracture risk}

Stratification of current DPP4-I use by cumulative and average daily dose did not show a significantly decreased risk of any fracture (Table 4). The adjusted OR for the highest cumulative dose was $1.08(95 \%$ CI: 0.76-1.54) and for highest average daily dose was 0.83 (95\% CI: 0.55-1.26). Stratification of current DPP4-I use by cumulative and average daily dose for the other fracture types did not result in a decreased risk of major osteoporotic (Table 4), hip, vertebral or radius/ulna fracture (data not shown).

\section{Result sensitivity analyses}

Adjusting the main analysis for current metformin use did not substantially change the results. Adjusted odds ratio with current DPP4-I use was 0.94 (95\% CI: 0.771.15), recent DPP4-I use was 0.74 (95\% CI: 0.58 0.95), past DPP4-I use was 0.93 (95\% CI: $0.74-1.16$ ) and distant DPP4-I use was 0.92 (95\% CI: 0.70-1.22).

\section{DISCUSSION}

The present study showed that current DPP4-I use was not associated with any fracture risk as compared to current use of other anti-hyperglycemic drugs. We further identified that the risk of other fractures was not associated with current DPP4-I use. Stratification of current DPP4-I use to cumulative and average daily dose did not show an association with fracture risk. However, recent DPP4-I use was associated with a significantly decreased risk of any fracture.

Our results are in agreement with a large clinical trial ( $\mathrm{n}=16492$, median follow-up 2.1 years) that compared saxagliptin (DPP4-I) to placebo and showed a non-significant relative fracture risk around 1.0.13 However, fractures were not the primary endpoint. The results are also in keeping with a cohort study using data from the Clinical Practice Research Datalink (CPRD) reporting that fracture risk was not associated with DPP4-I use as compared to use of other anti-hyperglycemic drugs. ${ }^{14}$ Similarly, Two meta-analyses of clinical trials on the effect of GLP-I 
USE OF DPP4-I AND RISK OF FRACTURE

Table 2. Use of DPP4-I and risk of any fracture

\begin{tabular}{|c|c|c|c|c|}
\hline Exposure & No. of cases $(\mathrm{N}=229145) \dagger$ & No. of controls $(\mathrm{N}=229145) \dagger$ & Crude OR $(95 \% \mathrm{CI})$ & Adjusted OR $(95 \%$ CI $)(\ddagger)$ \\
\hline Never NIAD use & 217623 & 218194 & $1.03(0.99-1.06)$ & $1.10(1.06-1.14)$ \\
\hline Past NIAD use & 3631 & 2815 & $1.33(1.25-1.41)$ & $1.12(1.05-1.20)$ \\
\hline $\begin{array}{l}\text { Current NIAD use } \\
\text { excluding incretin use }\end{array}$ & 6993 & 7209 & Reference & Reference \\
\hline $\begin{array}{l}\text { Distant DPP4-I use ( }>365 \text { days } \\
\text { before the index date) }\end{array}$ & 112 & 121 & $0.95(0.74-1.24)$ & $0.95(0.72-1.25)$ \\
\hline $\begin{array}{l}\text { Past DPP4-I use (183-365 days } \\
\text { before index date) }\end{array}$ & 181 & 186 & $1.00(0.81-1.23)$ & $0.96(0.77-1.20)$ \\
\hline $\begin{array}{l}\text { Recent DPP4-I use (92-182 days } \\
\text { before the index date) }\end{array}$ & 131 & 168 & $0.80(0.64-1.01)$ & $0.76(0.59-0.97)^{*}$ \\
\hline $\begin{array}{l}\text { Current DPP4-I use (1-91 days } \\
\text { before the index date) }\end{array}$ & 219 & 232 & $0.97(0.81-1.17)$ & $0.97(0.79-1.18)$ \\
\hline \multicolumn{5}{|l|}{ By sex } \\
\hline Males & 103 & 94 & $1.10(0.83-1.46)$ & $1.14(0.84-1.54)$ \\
\hline Females & 116 & 138 & $0.88(0.69-1.13)$ & $0.86(0.66-1.12)$ \\
\hline \multicolumn{5}{|l|}{ By age on index date } \\
\hline$<50$ years & 17 & 14 & $1.19(0.58-2.47)$ & $1.16(0.54-2.50)$ \\
\hline $50-59$ years & 50 & 51 & $1.07(0.71-1.61)$ & $1.06(0.68-1.64)$ \\
\hline $60-69$ years & 64 & 65 & $0.97(0.68-1.39)$ & $0.97(0.67-1.42)$ \\
\hline $70-79$ years & 49 & 58 & $0.83(0.56-1.22)$ & $0.89(0.59-1.36)$ \\
\hline $80+$ years & 39 & 44 & $0.96(0.62-1.48)$ & $0.92(0.58-1.44)$ \\
\hline
\end{tabular}

Abbreviations: OR: odds ratio; CI: confidence interval, DPP4-I: dipeptidyl peptidase 4 inhibitor; GLP-1 RA: glucagon-like peptide-1 receptor agonist.

Never NIAD use: no NIAD prescription before the index date.

Past NIAD use: most recent NIAD prescription over 91 days before index date.

Current NIAD use: most recent NIAD prescription within 91 days before index date.

*Statistically significant $(\mathrm{P}<0.05)$.

†The numbers do not sum to the total number of fractures because GLP-1 RA exposure is not shown.

¥Adjusted for history of cancer, COPD, fracture, alcoholism, rheumatoid arthritis, secondary osteoporosis, hyperthyroidism, retinopathy, neuropathy, heart failure and use of GLP-1 RA, glucocorticoids, statins, anxiolytics, hypnotics, antidepressants, antipsychotics, anti-Parkinson drugs, beta-blockers, thiazide diuretics, RAAS inhibitors, loop diuretics and antiarrhythmics.

RAs on fracture risk showed no association between GLP-1 RAs and fracture risk. ${ }^{25,26}$ As well as a retrospective cohort study comparing use of GLP-1 RAs to use of other anti-hyperglycemic drugs. ${ }^{27}$ Although GLP-1 RAs intervene on a different molecule than DPP4-I, the final effect on bone metabolism might be similar. ${ }^{3}$ Moreover, our results are supported by the results of a clinical trial investigating the effect of the DPP4-inhibitor vildagliptin on a bone resorption marker ${ }^{28}$ Compared to placebo, 44 weeks of treatment with vildagliptin was not associated with a decrease in postprandial markers of resorption, ${ }^{29}$ which indirectly supports our findings.

We note that our results are in contrast to a metaanalysis on the effect of DPP4-Is on fracture ${ }^{12}$ identifying that DPP4-I use was associated with a $40 \%$ reduction in fracture risk. However, this meta-analysis had several limitations, which may explain the discrepancies with our findings. Specifically, the mean duration of followup was only 35 weeks, the number of fractures was low $(n=63)$ and the outcome was not routinely collected. Based on the low number of fractures and the short duration an attenuation of the effect would be expected; nevertheless a $40 \%$ reduced fracture risk was found. In addition, 12 weeks of sitagliptin treatment was associated with a decreased bone resorption marker as compared to metformin use in postmenopausal diabetic women, which may support a beneficial effect of DPP4-I. ${ }^{29}$

Different mechanisms by which GLP-1 might result in increased bone formation ${ }^{30-32}$ have been previously hypothesised. GLP-1 and glucose-dependent insulinotropic polypeptides (GIP) are incretin hormones that are secreted by the intestine after food ingestion, whereas DPP4 is an enzyme that degrades incretin hormones quickly after secretion. ${ }^{3}$ DPP4-Is inhibit the enzymal degradation process and thereby prolong the half-life time of the incretin hormones.

In vitro studies have identified GLP-1 receptors on bone marrow stromal cells, ${ }^{33}$ immature osteoblast ${ }^{10}$ and osteocytes. ${ }^{9}$ Activation of the GLP-I receptor has shown to lead to increased osteoblast activity ${ }^{30}$ and inhibition of bone resorption ${ }^{34}$ that, theoretically, may lead to elevated bone formation and a reduced fracture risk. Similarly, GIP receptors have been identified on osteoblasts, ${ }^{11}$ osteoclasts ${ }^{35}$ and bone marrow stromal cells. ${ }^{36}$ Binding of GIP to its receptor stimulates osteoblast activity and inhibits osteoclast activity, ${ }^{10,11}$ which may increase bone formation and reduce fracture risk. Decreased bone turnover has been associated 
Table 3. Use of DPP4-I and risk fracture at different skeletal sites

\begin{tabular}{|c|c|c|c|c|}
\hline Fracture sites & No. of cases $\dagger$ & No. of controls $\dagger$ & Crude OR(95\% CI $)$ & Adjusted OR (95\% CI) \\
\hline Major osteoporotic & $\mathrm{N}=96774$ & $\mathrm{~N}=96774$ & - & - \\
\hline Never NIAD use & 90297 & 90677 & $1.02(0.97-1.07)$ & $1.07^{\ddagger}(1.02-1.13)$ \\
\hline Current NIAD use excl. incretin use & 3957 & 4058 & Reference & Reference \\
\hline Distant DPP4-I use ( $>365$ days before the index date) & 59 & 66 & $0.91(0.64-1.30)$ & $0.94(0.63-1.38)$ \\
\hline Past DPP4-I use (183-365 days before index date) & 96 & 106 & $0.92(0.70-1.22)$ & $0.95^{+}(0.71-1.29)$ \\
\hline Recent DPP4-I use (92-182 days before the index date) & 63 & 90 & $0.71(0.52-0.99)^{*}$ & $0.70^{\ddagger}(0.49-1.00)^{*}$ \\
\hline Current DPP4-I use (1-91 days before the index date) & 110 & 115 & $0.98(0.75-1.28)$ & $0.96^{\div}(0.72-1.28)$ \\
\hline Hip & $\mathrm{N}=24328$ & $N=24328$ & - & - \\
\hline Never NIAD use & 21923 & 22273 & $0.94(0.87-1.01)$ & $1.00^{\S}(0.92-1.09)$ \\
\hline Current NIAD use excl. incretin use & 1454 & 1388 & Reference & Reference \\
\hline Distant DPP4-I use ( $>365$ days before the index date) & 17 & 15 & $1.10(0.55-2.21)$ & $0.95^{\S}(0.42-2.15)$ \\
\hline Past DPP4-I use ( $183-365$ days before index date) & 25 & 28 & $0.85(0.49-1.46)$ & $0.80^{\S}(0.44-1.47)$ \\
\hline Recent DPP4-I use (92-182 days before the index date) & 17 & 24 & $0.67(0.36-1.26)$ & $0.76^{\S}(0.38-1.51)$ \\
\hline Current DPP4-I use (1-91 days before the index date) & 31 & 23 & $1.28(0.74-2.20)$ & $1.41^{\S}(0.78-2.52)$ \\
\hline Radius/ulna & $\mathrm{N}=47905$ & $\mathrm{~N}=47905$ & - & - \\
\hline Never NIAD use & 45848 & 45423 & $1.29(1.19-1.39)$ & $1.29^{\mathrm{II}}(1.19-1.40)$ \\
\hline Current NIAD use excl. incretin use & 1273 & 1617 & Reference & Reference \\
\hline Distant DPP4-I use ( $>365$ days before the index date) & 19 & 35 & $0.69(0.39-1.20)$ & $0.64^{\mathrm{II}}(0.35-1.17)$ \\
\hline Past DPP4-I use (183-365 days before index date) & 35 & 52 & $0.85(0.55-1.31)$ & $0.88^{\mathrm{II}}(0.56-1.38)$ \\
\hline Recent DPP4-I use (92-182 days before the index date) & 28 & 43 & $0.83(0.51-1.34)$ & $0.76^{\mathrm{II}}(0.46-1.28)$ \\
\hline Current DPP4-I use (1-91 days before the index date) & 44 & 60 & $0.93(0.63-1.38)$ & $0.84^{\mathbb{I}}(0.55-1.27)$ \\
\hline Vertebral & $\mathrm{N}=9004$ & $\mathrm{~N}=9004$ & - & - \\
\hline Never NIAD use & 8396 & 8450 & $1.01(0.87-1.17)$ & $1.11^{\|}(0.93-1.32)$ \\
\hline Current NIAD use excl. incretin use & 364 & 369 & Reference & Reference \\
\hline Distant DPP4-I use ( $>365$ days before the index date) & 4 & 8 & $0.52(0.16-1.73)$ & $1.01^{\|}(0.25-4.12)$ \\
\hline Past DPP4-I use (183-365 days before index date) & 14 & 8 & $1.90(0.75-4.82)$ & $2.34^{\| \prime}(0.87-6.32)$ \\
\hline Recent DPP4-I use (92-182 days before the index date) & 5 & 12 & $0.42(0.15-1.20)$ & $0.27^{\|}(0.08-0.90) *$ \\
\hline Current DPP4-I use (1-91 days before the index date) & 10 & 8 & $1.31(0.51-3.36)$ & $1.51^{\|}(0.54-4.23)$ \\
\hline
\end{tabular}

Abbreviations: OR: odds ratio; CI: confidence interval, DPP4-I: dipeptidyl peptidase 4 inhibitor; GLP-1 RA: glucagon-like peptide-1 receptor agonist; NIAD: non-insulin anti-diabetic-drugs.

Never NIAD use: no NIAD prescription before the index date.

Current NIAD use: most recent NIAD prescription within 91 days before index date.

* Statistically significant $(\mathrm{P}<0.05)$.

${ }^{\dagger}$ The numbers do not sum to the total number of fractures because past NIAD use and GLP-1 RA exposure are not shown.

*Adjusted for $(* *)$ and history of retinopathy, heart failure, COPD and use of glucocorticoids, statins, anxiolytics, antipsychotics, beta-blockers, thiazide diuretics, RAAS inhibitors and antiarrhythmics.

${ }^{\S}$ Adjusted for $(* *)$ and history of retinopathy, heart failure, COPD and use of statins, anxiolytics, RAAS inhibitors, antiarrhythmics, glucocorticoids and antipsychotics.

"Adjusted for (**) and use of beta-blockers, thiazide diuretics, RAAS inhibitors and calcium channel inhibitors.

"Adjusted for (**) and history of COPD and use of glucocorticoids, anxiolytics, RAAS inhibitors and antipsychotics.

**History of cancer, alcoholism, fracture, rheumatoid arthritis and secondary osteoporosis and use of GLP-1 RAs, antidepressants, anti-Parkinson drugs, loop diuretics and hypnotics.

with increased microdamage accumulation in animal studies. ${ }^{37}$ This might result in an increased risk of fracture because the bones become more brittle. So, it might be hypothesised that use of DPP4-Is may result in an increased risk of fracture because of the decreased bone turnover. However, a study investigating the frequency of cancellous bone microcracks in patients who had used bisphosphonates for more than 3 years as compared to controls did not show a different frequency of microcracks. ${ }^{38}$ In summary, more research is needed to better elucidate whether DPP4-Is are able to increase bone formation via the prolonging of the half-life of GLP-1 and GIP, and whether this effect is sufficient to alter osteoporotic fracture risk in humans.

Recent DPP4-I use showed a decreased association with risk of any fracture and risk of vertebral fracture.
Surprisingly, this was not found for other DPP4-I users (current, past and distant), which would have been expected when an underlying mechanism is causing this decreased fracture risk. Consequently, we consider these results to likely be due to chance, and believe they require further replication. The total number of vertebral fractures with recent DPP4-I use was rather low, and these results should therefore be interpreted with caution. Never and past NIAD use had an increased fracture risk as compared to current use of other anti-hyperglycemic drugs, which was also unexpected. Unfortunately, we were unable to adjust our analysis for body mass index (BMI), which has been shown to decrease fracture risk. ${ }^{39}$ Because an elevated BMI is a risk factor for diabetes, our finding that the increased risk associated with never NIAD 
USE OF DPP4-I AND RISK OF FRACTURE

Table 4. Current use of DPP4-I stratified by cumulative and average daily dose and risk of any and major osteoporotic fracture

\begin{tabular}{|c|c|c|c|c|c|c|}
\hline \multirow[b]{2}{*}{ Exposure } & \multicolumn{3}{|c|}{ Any fracture } & \multicolumn{3}{|c|}{ Major osteoporotic fracture } \\
\hline & $\begin{array}{c}\text { No. of cases } \\
(\mathrm{N}=229145) \dagger\end{array}$ & $\begin{array}{l}\text { No. of controls } \\
(\mathrm{N}=229145) \dagger\end{array}$ & $\begin{array}{l}\text { Adjusted OR } \\
(95 \% \mathrm{CI})^{\ddagger}\end{array}$ & $\begin{array}{l}\text { No. of cases } \\
(\mathrm{N}=96774)\end{array}$ & $\begin{array}{l}\text { No. of controls } \\
(\mathrm{N}=96774)\end{array}$ & $\begin{array}{l}\text { Adjusted OR } \\
(95 \% \mathrm{CI})^{\S}\end{array}$ \\
\hline Current NIAD use excl. incretin use & 6993 & 7209 & Reference & 3957 & 4058 & Reference \\
\hline Current DPP4-I use & 219 & 232 & $0.97(0.79-1.18)$ & 110 & 115 & $0.96(0.72-1.28)$ \\
\hline \multicolumn{7}{|l|}{ By cumulative exposure el $^{\mathrm{I}}$} \\
\hline$\leq 9.1 \mathrm{~g}$ & 58 & 64 & $0.82(0.56-1.20)$ & 34 & 35 & $0.87(0.52-1.46)$ \\
\hline $9.2-18.2 \mathrm{~g}$ & 46 & 49 & $0.99(0.65-1.52)$ & 20 & 28 & $0.79(0.43-1.46)$ \\
\hline $18.3-36.5 \mathrm{~g}$ & 44 & 50 & $0.97(0.63-1.49)$ & 19 & 17 & $1.26(0.63-2.54)$ \\
\hline$>36.5 \mathrm{~g}$ & 71 & 69 & $1.08(0.76-1.54)$ & 37 & 35 & $1.04(0.64-1.71)$ \\
\hline \multicolumn{7}{|l|}{ By average daily dose ${ }^{\mathrm{q}}$} \\
\hline$<100 \mathrm{mg} /$ day & 44 & 59 & $1.17(0.75-1.81)$ & 22 & 32 & $1.09(0.56-2.11)$ \\
\hline $100-149 \mathrm{mg} /$ day & 123 & 133 & $0.96(0.74-1.24)$ & 64 & 65 & $1.01(0.70-1.46)$ \\
\hline$\geq 150 \mathrm{mg} /$ day & 52 & 40 & $0.83(0.55-1.26)$ & 24 & 18 & $0.76(0.42-1.38)$ \\
\hline Recent DPP4-I use & 131 & 168 & $0.76(0.59-0.97)^{*}$ & 63 & 90 & $0.71(0.50-1.01)$ \\
\hline Past DPP4-I use & 181 & 186 & $0.96(0.77-1.20)$ & 96 & 106 & $0.96(0.71-1.30)$ \\
\hline Distant past DPP4-I use & 112 & 121 & $0.95(0.72-1.25)$ & 59 & 66 & $0.90(0.61-1.34)$ \\
\hline
\end{tabular}

Abbreviations: OR: odds ratio; CI: confidence interval; DPP4-I: dipeptidyl peptidase 4 inhibitor; GLP-1 RAs: glucagon-like peptide-1 receptor agonists:

NIAD: non-insulin anti-diabetic-drugs.

Current NIAD use: most recent NIAD prescription within 91 days before index date.

Current DPP4-I use: most recent DPP4-I prescription within 91 days before index date.

Recent DPP4-I use: most recent DPP4-I prescription within 92-182 days before index date.

Past DPP4-I use: most recent DPP4-I prescription within 183-365 days before index date.

Distant DPP4-I use: most recent DPP4-I prescription more than 365 days before index date.

*Statistically significant $(\mathrm{P}<0.05)$.

${ }^{\dagger}$ The numbers do not sum to the total number of fractures because never incretin use, past NIAD use and GLP-1 RA exposure are not shown.

¥Adjusted for use history of cancer, alcoholism, COPD, fracture, rheumatoid arthritis, hyperthyroidism, secondary osteoporosis, retinopathy, neuropathy and heart failure and use of GLP-1 RAs, glucocorticoids, statins, antidepressants, anxiolytics, hypnotics, antipsychotics, anti-Parkinson drugs, beta-blockers, thiazide diuretics, RAAS inhibitors, loop diuretics and antiarrhythmics.

${ }^{\S}$ Adjusted for $(\ddagger)$, but not for hyperthyroidism and neuropathy.

"Expressed as sitagliptin equivalents.

use is a by-product of higher BMI among the current NIAD users. We also note that our past NIAD user group includes patients with type 2 diabetes mellitus receiving insulin therapy. Prior evidence has identified that fracture risk doubles for type 2 diabetes mellitus patients who use insulin compared to patients who receive strictly oral mono-therapy. ${ }^{2}$

Strengths of this study include the nation-wide population based design, large sample size, the validity of data and the completeness of the Danish Health Registries. In addition, fractures are well captured in the hospital system of Denmark. ${ }^{15}$ Another strength is the fact that data are prospectively collected, which circumvents any recall bias. Unfortunately, there was no data available about life style factors, such as BMI and smoking, or lab tests. For example, haemoglobin A1c (HbA1c) values, which might be potential confounders, were not captured in our data. However, as a proxy for $\mathrm{HbA} 1 \mathrm{c} /$ poor diabetes control, we corrected our analyses for known complications of diabetes, such as neuropathy and retinopathy, and we used current use of other anti-hyperglycemic drugs (with the exception of insulin) as a proxy for diabetes. However, it is acknowledged that some residual confounding may still be present. For example, current NIAD use included current TZD and insulin use, which has been associated with an elevated fracture risk. $^{4-7}$ The result of this bias in the reference category may be an observed artificial inverse association between DPP4-I use and risk of fracture, which could have falsely supported our hypothesis. However, we did not observe an inverse association between DPP4-I use and risk of fracture. We might not have been able to fully adjust for diabetes severity which could have masked a true decreased risk of fracture with use of DPP4-Is. When studying a population with diabetes patients only, the adjusted diabetic complication severity index (aDCSI) may be used to correct for diabetes severity. ${ }^{40} \mathrm{We}$ further note that metformin use has been associated with a reduced fracture risk. While our referent group included current metformin users, which may have limited our findings, we did not find a decreased risk of fracture associated with current use of DPP4-I after adjusting for current metformin use. Another limitation of our study was the relatively short mean duration (47weeks) of DPP4-I use (time from first prescription to index date). However, a meta-analysis of clinical trials investigating the effect 


\section{J. H. M. DRIESSEN ET AL.}

of DPP4-I use on risk of fracture showed a decreased effect on fracture risk with a mean duration of 35 weeks. ${ }^{12}$

In summary, we showed in a population-based case-control study that short-term DPP4-I use was not associated with fracture risk as compared to use of other anti-hyperglycemic drugs. Additionally, increasing daily dose and cumulative DPP4-I exposure were also not associated with fracture risk. However, more research is needed to assess the effect of longterm DPP4-I use on the risk of fracture.

\section{CONFLICT OF INTEREST}

Utrecht, JD, FV and $\mathrm{AB}$ declare that they are employed by the Division of Pharmacoepidemiology and Clinical Pharmacology at Utrecht Institute for Pharmaceutical Sciences, which has received unrestricted funding from the Netherlands Organisation for Health Research and Development (ZonMW), the Dutch Health Care Insurance Board (CVZ), the Royal Dutch Pharmacists Association (KNMP), the privatepublic funded Top Institute Pharma (www.tipharma. $\mathrm{nl}$ ), including co-funding from universities, government and industry, the EU Innovative Medicines Initiative (IMI), the EU 7th Framework Program (FP7) and the Dutch Ministry of Health and Industry (including GlaxoSmithKline, Pfizer and others).

AB is supported by a Canadian Institutes of Health Research (CIHR) Post Doctoral Fellowship.

\section{KEY POINTS}

- Limited data available about potential protective effect of DPP4-Is on fracture risk

- Short-term DPP4-I use was not associated with fracture risk as compared to use of other antihyperglycemic drugs.

- Increasing daily dose and cumulative DPP4-I exposure were also not associated with fracture risk.

- More research is needed to assess the effect of long-term DPP4-I use on the risk of fracture.

\section{REFERENCES}

1. Vestergaard P. Discrepancies in bone mineral density and fracture risk in patients with type 1 and type 2 diabetes-a meta-analysis. Osteoporos Int 2007; 18(4): 427-444.

2. Carnevale V, Romagnoli E, D'Erasmo E. Skeletal involvement in patients with diabetes mellitus. Diabetes Metab Res Rev 2004; 20(3): 196-204.

3. Montagnani A, Gonnelli S. Antidiabetic therapy effects on bone metabolism and fracture risk. Diabetes Obes Metab 2013; 15(9): 784-791.
4. Bazelier MT, Gallagher AM, van Staa TP, et al. Use of thiazolidinediones and risk of osteoporotic fracture: disease or drugs? Pharmacoepidemiol Drug Saf 2012; 21(5): 507-514.

5. Bazelier MT, Vestergaard P, Gallagher AM, et al. Risk of fracture with thiazolidinediones: disease or drugs? Calcif Tissue Int 2012; 26(9): 2271-2279.

6. Betteridge DJ. Thiazolidinediones and fracture risk in patients with Type 2 diabetes. Diabet Med 2011; 28(7): 759-771.

7. Schwartz AV, Vittinghoff E, Bauer DC, et al. Association of BMD and FRAX score with risk of fracture in older adults with type 2 diabetes. JAMA 2011; 305(21): 2184-2192.

8. Vestergaard P, Rejnmark L, Mosekilde L. Relative fracture risk in patients with diabetes mellitus, and the impact of insulin and oral antidiabetic medication on relative fracture risk. Diabetologia 2005; 48(7): 1292-1299.

9. Kim JY, Lee SK, Jo KJ, et al. Exendin-4 increases bone mineral density in type 2 diabetic OLETF rats potentially through the down-regulation of SOST/sclerostin in osteocytes. Life Sci 2013;21;92(10): 533-540.

10. Phillips LK, Prins JB. Update on incretin hormones. Ann N Y Acad Sci 2011; 1243: E55-E74.

11. Bollag RJ, Zhong Q, Phillips P, et al. Osteoblast-derived cells express functional glucose-dependent insulinotropic peptide receptors. Endocrinology 2000; 141(3): 1228-1235.

12. Monami M, Dicembrini I, Antenore A, Mannucci E. Dipeptidyl peptidase-4 inhibitors and bone fractures: a meta-analysis of randomized clinical trials. Diabetes Care 2011; 34(11): 2474-2476.

13. Scirica BM, Bhatt DL, Braunwald E, et al. Saxagliptin and cardiovascular outcomes in patients with type 2 diabetes mellitus. N Engl J Med 2013; 369(14): $1317-1326$.

14. Driessen JH, van Onzenoort HA, Henry RM, et al. Use of dipeptidyl peptidase-4 inhibitors for type 2 diabetes mellitus and risk of fracture. Bone 2014; 68: 124-130.

15. Vestergaard $P$, Mosekilde L. Fracture risk in patients with celiac disease, Crohn's disease, and ulcerative colitis: a nationwide follow-up study of 16,416 patients in Denmark. Am J Epidemiol 2002; 156(1): 1-10.

16. Frank L. Epidemiology. When an entire country is a cohort. Science 2000; 287: 2398-2399.

17. Andersen T, Madsen M, Jørgensen J, Mellemkjær L, Olsen J. The Danish National Hospital Register. Dan Med Bull 1999; 46: 263-268.

18. Wacholder S, McLaughlin J, Silverman D, Mandel J. Selection of controls in case-control studies. I. Principles. Am J Epidemiol 1992; 135: 1019-1028.

19. FRAX. WHO fracture risk assessment tool. 2001. shef.ac.uk. www.shef.ac.uk/ FRAX/ index.aspx.

20. Anonymous. ATC classification index with DDDs 2002. Nydalen, WHO Collaborating Centre for Drug Statistics Methodology, Norwegian Institute of Public Health, 2002.

21. Klop C, de Vries F, Vinks T, et al. Increase in prophylaxis of glucocorticoidinduced osteoporosis by pharmacist feedback: a randomised controlled trial. Osteoporos Int 2014; 25(1): 385-392.

22. Prieto-Alhambra D, Petri H, Goldenberg JS, et al. Excess risk of hip fractures attributable to the use of antidepressants in five European countries and the USA. Osteoporos Int 2014; 25(3): 847-855.

23. Khong TP, de Vries F, Goldenberg JS, et al. Potential impact of benzodiazepine use on the rate of hip fractures in five large European countries and the United States. Calcif Tissue Int 2012; 91(1): 24-31.

24. Pouwels S, Bazelier MT, de Boer A, et al. Risk of fracture in patients with Parkinson's disease. Osteoporos Int 2013; 24(8): 2283-2290.

25. Mabilleau G, Mieczkowska A, Chappard D. Use of glucagon-like peptide-1 receptor agonists and bone fractures: a meta-analysis of randomized clinical trials. $J$ Diabetes 2014; 6(3): 260-266.

26. Su B, Sheng H, Zhang M, et al. Risk of bone fractures associated with glucagonlike peptide-1 receptor agonists' treatment: a meta-analysis of randomized controlled trials. Endocrine 2014; 48(1): 107-115.

27. Driessen JH, Henry RM, van Onzenoort HA, et al. Bone fracture risk is not associated with the use of glucagon-like peptide-1 receptor agonists: a population-based cohort analysis. Calcif Tissue Int 2015; 97(2): 104-112.

28. Bunck MC, Poelma M, Eekhoff EM, et al. Effects of vildagliptin on postprandial markers of bone resorption and calcium homeostasis in recently diagnosed, wellcontrolled type 2 diabetes patients. J Diabetes 2012; 4(2): 181-185.

29. Hegazy SK. Evaluation of the anti-osteoporotic effects of metformin and sitagliptin in postmenopausal diabetic women. J Bone Miner Metab.2014; 33(2): 207-212.

30. Nuche-Berenguer B, Moreno P, Esbrit P, et al. Effect of GLP-1 treatment on bone turnover in normal, type 2 diabetic, and insulin-resistant states. Calcif Tissue Int 2009; 84: 453-461.

31. Nuche-Berenguer B, Moreno P, Portal-Nuñez S, Dapía S, Esbrit P, VillanuevaPeñacarrillo ML. Exendin-4 exerts osteogenic actions in insulin-resistant and type 2 diabetic states. Regul Pept 2010; 159(1-3): 61-66.

32. Moreno P, Nuche-Berenguer B, Gutiérrez-Rojas I, et al. Normalizing action of exendin-4 and GLP-1 in the glucose metabolism of extrapancreatic tissues in insulin-resistant and type 2 diabetic states. J Mol Endocrinol 2012; 48: 37-47. 


\section{USE OF DPP4-I AND RISK OF FRACTURE}

33. Sanz C, Vázquez P, Blázquez C, Barrio PA, Alvarez Mdel M, Blázquez E. Signaling and biological effects of glucagon-like peptide 1 on the differentiation of mesenchymal stem cells from human bone marrow. Am J Physiol Endocrinol Metab 2010; 298(3): E634-E643.

34. Lamari Y, Boissard C, Moukhtar MS, Jullienne A, Rosselin G, Garel JM. Expression of glucagon-like peptide 1 receptor in a murine $\mathrm{C}$ cell line: regulation of calcitonin gene by glucagon-like peptide 1. FEBS Lett 1996; 393(2-3): $248-252$.

35. Zhong Q, Itokawa T, Sridhar S, et al. Effects of glucose-dependent insulinotropic peptide on osteoclast function. Am J Physiol Endocrinol Metab 2007; 292(2): E543-E548.

36. Ding KH, Shi XM, Zhong Q, et al. Impact of glucose-dependent insulinotropic peptide on age-induced bone loss. J Bone Miner Res 2008; 23(4): 536-543.
37. Johnston CC, Burr DB. Suppressed bone turnover by bisphosphonates increases microdamage accumulation and reduces some biomechanical properties in dog rib. J Bone Miner Res 2000; 15: 613-620.

38. Chapurlat RD, Arlot M, Burt-Pichat B, Chavassieux P, Roux JP, Portero-Muzy $\mathrm{N}$, Delmas PD. Microcrack frequency and bone remodeling in postmenopausal osteoporotic women on long-term bisphosphonates: a bone biopsy study. J Bone Miner Res 2007; 22(10): 1502-1509.

39. Cummings SR, Nevitt MC, Browner WS, Stone K, Fox KM, Ensrud KE, Cauley J, Black D, Vogt TM. Risk factors for hip fracture in white women. Study of Osteoporotic Fractures Research Group. N Engl J Med 1995; 332(12): 767-773.

40. Chang HY, Weiner JP, Richards TM, Bleich SN, Segal JB. Validating the adapted Diabetes Complications Severity Index in claims data. Am J Manag Care 2012; 18(11): 721-726. 